\title{
Unravelling English Language Space Constituted in Model School Construction in Nepal
}

- Kamal Raj Devkota, PhD

Lecturer, CERID, TU

\begin{abstract}
School Sector Development Plan (SSDP, 2016-2023) has envisaged the establishment and operation of 'model schools' to demonstrate improved management and teaching-learning therein. One thousand secondary schools representing all provinces and districts are planned to be developed as model schools, and three hundred and five have already been selected for initiating the project in 2017/18. Model School Guideline has been developed in the framework of SSDP; and in accordance with that, the selected schools are provided with certain financial support for building infrastructure, improving classroom delivery and instructional activities, and bringing efficiency in school management. Based on the fieldwork in four sample schools of Nepal, this study has unraveled how these 'model' schools have understood, experienced and enacted with English language space (ELS) in the course of model school construction. The analysis of the field data especially derived from school observation, qualitative research interviews and Focus Group Discussions with teachers, School Management Committee members and students unpacks how English language, which is often defined as the key for students' and parents' choice of school, is equally associated with confusion and ambivalence in the construction of model schools in Nepal. The analysis shows that the confusion and ambivalence concentrate around three major constructs: ELS as instrumental to school sustainability, ELS as a conflicting zone, and ELS as the educultural reality in the current educational discourses.
\end{abstract}

Keywords/terms: Model school, English language space, quality education, school pedagogy

\section{Introduction}

School Sector Development Plan (SSDP, 2016-2023) has envisaged the establishment and operation of a number of 'model schools' to demonstrate improved teaching-learning and student learning outcomes. Accordingly, it has been said that one thousand secondary schools will be developed as model schools representing all provinces and districts of Nepal. Three 
hundred and five of them have been selected by the FY 2017/18. The government has prepared Model School Guidelines (MSGs) under the SSDP 2016-2023 framework, and in accordance with that, selected schools have been supported with some certain incentives for developing physical infrastructure, improving instructional activities, and bringing efficiency in school management. In procedural terms, the schools that have demonstrated some possibilities in terms of infrastructure, human resource and school governance have been encouraged to prepare their multi-year quality improvement plans. The plans are then evaluated along with some feasibility studies. On this ground, the government of Nepal (GoN) has approved the schools for development as models. Following the criteria of model school selection, the school needs to have run classes from Grade 1 to 12 , should have adequate land of its own, must be located in a safe zone in terms of environment. And, the school must have written commitment from School Management Committee (SMC), and recommendation from the local government. (MoEST, 2016)

Based on these criteria, indicators have been designed to assess how far a school is potential to be developed as the model school. These indicators include teaching subjects for grade 11 and 12, adequacy of land for hostel and outdoor games, ratio of students in school, location of the school, result of school level examination, availability of electricity and internet, and also the accessibility to the local community. The schools which submit the application are assessed on the basis of these indicators. In collaboration with concerned development partners, MoEST/CEHRD (Centre for Education and Human Resource Development) allocates NRs. 1.5 million to the selected schools, and the schools are directed to proceed ahead with the provision of a fulltime head teacher and subject teachers for Math, Science and English subjects. The schools are directed to initiate physical infrastructure, human resource development and quality improvement in academic aspect (pedagogical activities).

As per the MSGs, some the schools observed during the fieldwork have initiated their internal policies, and some others have implemented certain activities including teacher training, ICT development, building construction, and retrofitting of the earthquake-affected buildings. Along with the mentioned activities, these schools have designed certain policies and implementation framework to improve instructional activities. One among 
such activities includes the effort of creating dominant ELS either through the allocation of more period loads to the English language subject, or through the provision of English-as-the-medium-of-instruction (EMI) for instructing other subjects as well. Almost all sample schools have run EMI as part of improvement in the quality of their pedagogical activities. However, schools were found equally inflicted with a number of contestant meanings, controversies and paradoxes in practice. On this ground, this study unravels the field experience of how the 'model schools' have constituted ELS in the process of model school construction. As well, it has explored how the schools have understood, experienced and enacted ELS in the course of model school construction in their educultural context.

\section{Schools: Site of contestant linguistic space}

'School' in a multilingual society is often understood as a contestant linguistic space where more languages interact in simultaneous and complex manner. Students from diverse linguistic communities attend the school and classroom carrying their own life histories and linguacultural habitus. However, a very few languages or a language that enjoy(s) wider communication among the people, or the ones that enjoy more demand in the current linguistic market (Park and Wee, 2012) play a dominant role in school pedagogies. Students whose mother tongues are more dominant in school pedagogies get more privileged compared to those who have to learn the languages other than their mother tongues. Of course, "complex multilingual societies are the norm in many parts of the world" (Little and others, 2014). As UNESCO (2003) describes, societal multilingualism can be considered as a way of life, not a problem to be solved; and any 'problems' posed by multilingualism should not be attributed to culturally or linguistically diverse children, but to educational systems that have not been adapted to the complex realities and do not provide quality education that takes learners' needs into consideration (cited in, Tylor, 2013 , p. 257). Such a conception of understanding multilingualism and multilinguals is "a shift from language isolation policies of language teaching and assessment towards more holistic approaches that consider language-asresource and promote the use of the whole linguistic repertoire" (Gorter and Cenoz, 2017).

However, such a conception of language-as-resource and linguistic reciprocity has not been systematic in the schools and language classrooms in many developing societies. In this regard, Gorter and Cenoz argue: 
"Language diversity and minority languages are often conceived as a social problem, and solving the problem of such languages is then seen as requiring a technical problem" (p. 232). Therefore, the reality in many classrooms even today is that the linguistic needs of bi/plurilingual children are not met (Helot and Laoire, 2011). Monolingual ideologies constituted in the social and cultural spaces value certain languages and devalue the rest. And, the languages which are often devalued have limited space of use in schools and classrooms as well. Even the parents and schoolchildren from these linguistic communities are reinforced not to show their interest and desire in learning and sustaining their own mother tongues. Rather, they contribute to reproduce the cultural capital [linguistic habitus] of the dominant class, thus complying with their own subjugation in their edu-cultural space (Garcia and others, 2009).

Such an uneven linguistic situation has become a strong reference for many researchers in Nepali educultural context. To review a few, Awasthi (2008) observes a strong influence of "western ideology of monolingualism" that reinforces 'multilingual restrictionism', which in turn, played a decisive role in framing the policies and pedagogies of Nepal's modern schooling/ education (p. 22). In a similar tone, Phyak (2015) argues how monolingual ideologies have been reproduced through the iconization of Nepali as the national language, and English as the language of technology and the global linguistic marketplace. He further argues "by reproducing the monolingual ideology, language policies in education and other public spheres are ignoring the profound importance of indigenous languages, culture, identities, and epistemologies" (n.d). The resultant effect could be observed in formal schooling trajectories of the children from diverse ethnolinguistic social groups. Khanal (2017) has explored how "the children from ethnic minorities are subjected to experience symbolic violence in schools' everyday interactions, practices and dispositions" (p. 1).

English language education is closely associated with formal schooling in Nepal. Though the country was never colonised in its geographical history, Nepal experienced a strong influence of Macaulay system of education of the then British-India. On this ground, English language education became a key social agent of shaping 'bikasi/abikasi', 'educated/uneducated' and 'civilised/uncivilised' subjectivities among the Nepalis (Shrestha, 1997). On the one hand, "English is seen as a bridge between the social divide and a 
means for upward social mobility. It is also associated with modernity, being up-to-date, civilised and democratic" (Giri, 2010, p. 93). On the other hand, these very ideals are quite distant for many people who are often struggling on social, cultural, economic and linguistic grounds. English language and English education have stood as the mechanisms of reinforcing social inequalities and class sensitivity (Leichty, 2003). For the last few decades, along with Nepal's growing interaction with the emergent global cultural flows, English language and English-prioritised schooling have been more stimulating and penetrating in the construction of social difference and differentiation on the ground of caste, class, gender and linguistic backdrop (Devkota, 2018).

By these empirical insights, this ethnographic study critically examined how schools have become the contestant linguistic space in terms of meanings, pedagogies and enactments. On the one hand, model schools are understood, in policy terms, as the spaces to expose more English language knowledge and communication skills so as to prepare the schoolchildren for the global market today. On the other hand, the schoolchildren themselves belong to diverse linguistic communities, and do come to the schools and classrooms with their own linguistic habitus. This concomitant situation is conflicting and paradoxical rather than straightforward. The monolingual ideology often overrides the multilingual realities of model schools and classrooms. In this very contestant space between monolingual ideology against multilingual diversity, this study unravels ELS in model school construction in Nepal.

\section{Field: Sample schools}

The fieldwork for this study took place in four of the model schools that the GoN announced in the FY 2017/18. Two schools were located in Kathmandu Valley (School A and School B) and the remaining two outside (School C and School D). School A, founded along with the mass schooling movement in the 1950s, has now more than three thousand students enrolled from Kindergarten to higher secondary grades. The school is more fascinated to its Science stream in the higher secondary grades. Yet, somehow equal number of students are studying in Management stream as well. Altogether 123 teachers are working on permanent and part-time basis. Only 53 teachers are paid with government salary. It indicates that more than half of the teachers are paid with schools' internal resources. The school has attracted a large number of students by pronouncing itself as the fully English-medium school 
from Kindergarten to grade eight. Yet, to address the new enrollees coming from Nepali-medium school background, the school has also managed Nepali-as-the-medium-of-instruction (NMI) in one of the five sections in grade 9 and 10. Of course, the school has provided the choice of medium-ofinstruction to the students. Yet, it has also conflicting consequences among the students who come from diverse ethnic, linguistic and social backgrounds. As the principal reiterated, the school has a very limited space and almost insufficient classrooms for the huge number of students accommodated therein.

School B, located in the outskirts of Kathmandu valley, was founded in the late 1960s. The school now accommodates around five hundred students including a section for the disabled. Located on the top of a small hill that opens the landscape of Kathmandu valley, the school does not have a big land-space of its own. Yet, since it is situated little farther from the nearby community, the school seems peaceful. However, the occasional gatherings of the local people to worship the goddess in the temple built up beside the main school building sometimes disturbs the school activities. For the last few years, the school has pronounced itself as the English-medium school. As the principal stated, "when the enrollment of students decreased significantly, the school was forced to announce English-as-the-medium-ofinstruction (EMI) to sustain itself, so English has now become the weapon for sustaining this school" [Fieldnotes, 2018]. The school has also managed more period loads to the English subject as well. Teachers and students have been instructed to use English-only in the school premises. Yet, as the teachers explained during focused-group-discussions (FGDs), they teach English-medium textbooks for rest of the subjects as well, but the classroom discussion proceeds in Nepali language instead of English.

School C is located in the central part of the local town in the Western hill in Nepal. The school was founded in the late 1950s, and now it accommodates around eighteen hundred students from Kindergarten to higher secondary grades. Higher secondary grades run in Science, Management, Education and Humanities streams. Out of ninety-four teachers, only forty-two are in permanent position, and salaries of these teachers are paid by the government. This implies that still a large number of teachers are contracted by the school itself. The Principal reported that this is almost impossible to run the classes if the school does not hire additional teachers by paying them 
from its internal sources. The school has announced a full-fledged Englishmedium up to grade 8. And for grade 9 and 10, some sections run in NMI, and some more sections in EMI. However, as some young teachers explained during fieldwork, their ultimate goal is to run clases in 'sound English medium'. However, some other teachers expressed their confusion if English-only assures quality in education as per the current demand of the nation. Nevertheless, the school has managed more English language exposure by allocating maximum period loads to English subjects, EMI to all sections except for the sections where there are 'English-weak' students; and there is the code of conduct for teachers and students for creating English language speaking environment.

School D is located in the central part of a local town in one of the Tarai districts of Nepal. The school was founded in the mid 1960s when the community leaders realised that the community was lagging behind due to having no access to education for their children. The school now accommodates around fourteen hundred students from Kindergarten to higher secondary grades. Out of thirty-seven teachers, only twenty-three are government-salaried. Thus, still a large number of teachers are contracted by the school itself using its internal resources for their remuneration. The school was once about to be closed due to the very low enrollment of children. However, as the school principal reiterated, "When we announced our school as English-medium, students' enrolment increased" [Fieldnote, 2019]. As he added, the school has managed more period loads for English subject from pre-primary section to upper basic level. However, the school has managed Nepali as well as English-medium sections for Grade 9 and 10. The principal explained that the Nepali medium sections are mainly for those students who are comparatively weaker in English language and feel very difficult to attend the SEE exam in English medium. During FGDs, most of the teachers explained that division of the students of the same grade into Nepali-medium and English-medium sections has attributed some negative conseuqences among students. Sometimes such a practice has encouraged the schoolchildren feel strong-weak subjectivities on the ground of English language exposure they get in the school premises.

\section{Methods and analytical framework}

This study applied ethnographic research design which involved qualitative interviewing, focus group discussions (FGDs), observation and document 
study in the process of data collection. Fieldwork took place in the sample schools. I observed teacher as well as student behavior and activities in natural settings. Particular focus remained to unpack social meanings that the school actors construct on English language, English language teaching and learning (ELT/ELL) as well as English-as-the-medium-of-instruction (EMI). I followed the mentioned 'ethnographic methods' to capture how schools had constructed 'ELS' in the process of model school construction. Informal interviews and FGDs with teachers and students were used as the major tools in order to unpack how they constitute meanings and understanding on ELS. The policy documents and minutes were considered important for exploring how schools define ELS in their policy terms. Fieldnotes were prepared in the researcher's diary while making informal interviews with students and teachers, and also observing classrooms.

After the fieldwork, the interviews, FGDs and observation fieldnotes were transcribed and translated into English. Especially, while analysing data, I applied 'thematic analysis approach' outlined by Braun and Clarke (2006). I first familiarised myself with the data, data sources, then transcribed and translated that into readable form. Second, I generated the initial codes manually. Third, I categorised the codes in order to build up certain themes. Fourth, I reviewed the themes so as to assure if these themes capture the major meanings expressed by the data. Fifth, I defined and named the themes. And finally, I made a discussion on the themes emerged from the field. The discussion proceeded on the basis of field reflexivity, review of school ethnographies in diverse school/educational contexts, and researcher subjectivity to perceive the constructed reality.

\section{Results and discussion}

This section makes discussion on the major themes that have been constituted in order to construct ELS in the process of model school construction.

\section{ELS as instrumental to school sustainability}

As most of the sample schools recapitulated their past experience, they have faced the situation of decrease in student enrollment significantly until they announced more period loads for English language subjects and EMI in their school policies and pedagogies. Although it was difficult to implement EMI in their schools, they were compelled to initiate it to address the parents' 
demand. However, many teachers during FGDs explained that they were forced to do so because of the growing demand of English language communication skills in the society. As one of the teachers of School C said, "We could not escape from it, as the parents and local community demanded us to initiate more English exposure to the children; so we started it without any question" [Interview, 2019]. However, as another teacher of the same school expressed, "We were not ready when we started EMI and more English medium subjects. We didn't have sufficient teachers who could efficiently handle the class in English; but we started, otherwise we could not enroll students" [Interview, 2019]. The experience of these teachers is not unique to School $\mathrm{C}$ alone. Similar experience was found in the case of School A, School B and School D. The principal of the School A explained: "Many private boarding schools nearby already had English medium, these schools had gradually attracted more students not because of their teachers, not because of the space in their premises, but because of more time for English language subject, EMI and thus more English textbooks, so we had to manage all that in order to sustain ourselves in the market." [Interview, 2019].

The meanings that these teachers constructed in regard to constituting more ELS in their respective schools are deeply connected to 'school sustainability'. In the beginning, some missionary schools established in the urban spaces of Nepal including Kathmandu had initiated more ELS in their respective schools. These schools were mainly focused to quench the thirst of the elite and the middle class people in Nepal (Devkota, 2018). However, along with growing influence of neoliberalism, education became the fertile land of investment and business. Accordingly, privately run business schools were mushroomed in the urban and semi-urban areas. These schools not only institutionalised more ELS in schooling but also institutionalised the schoolinitiated social division through 'class sensitivity' among the parents and schoolchildren (Liechty, 2003). Equally, these schools seriously challenged the government-aided public schools which were mostly Nepali medium. As parents chose English medium private schools for their children, enrollment of children in many public schools decreased. Of course, no fundamental study has been made if quality service of the private schools mattered in this regard. Yet, parents and their children are still motivated a lot towards the privately run English medium schools. 
Unravelling English Language Space Constituted in Model School Construction...

\section{ELS as a conflicting zone}

The analysis of the data situates that ELS has become a conflicting zone in model school pedagogies. ELS constituted through more period loads to English subjects, EMI and more English medium textbooks all are guided by monolingual ideology. However, such a monolingual ideology seriously contrasts with multilingual/plurilingual realities of the schools and classrooms. As I observed the classrooms of the model schools, I found that the students from three to five mother tongues sit together. This is the reality whether that is in the classrooms of sample School A and School B of Kathmandu Valley, or that of sample school $\mathrm{C}$ and school D outside. However, knowledge of the mother tongues they acquire in their family environment hardly becomes the reference/medium of learning at schools. This leads most of the schoolchildren not achieving the expected outcomes. As I was reported by the students whose early school background for junior grades was not English medium, they were experiencing very difficult time to learn the subject matter taught in the schools and classrooms. Sohan, a Grade 9 student from School A, explained his experience as, "I didn't go to English medium schools for my primary grades, but now the school is in English medium for grade 6, 7 and 8, I don't understand what the teachers speak in English, I understand a little when they speak in Nepali, but Maithili, my mother tongue is not used at all; textbooks are all in English, it is really difficult for me." [Interview, 2019] Similar experience was shared by Seema, a Gurung girl from School C. She said, "I was born and brought up in mountainous region, I spoke only my language, Gurung, and a little Nepali at my school there, but here the school is English medium and the books are all in English, how could I understand? It is rather difficult for me to pass grade 8." [Interview, 2019] The narratives of these students implies how ELS has become a conflicting zone between enforced monolingual ideology and situated plurilingual realities.

Another meaning constructed in schools and classrooms is if more ELS is quality education at all. I found that the sample schools are in serious debate as regards whether the sole English language exposure attributes quality education for the students. Some teachers especially those who have longer experience in their career often expressed their dissatisfaction against creating more English language space in the schools and classrooms. During FGDs, they recapped their past and claimed that their service delivery through Nepali medium was better enough for ensuring good performance of the schools. 
However, the teachers of the younger generation often expressed the reason as to why English language communication skills have been a dire need for the young generation. As they pointed out, unlike past, Nepal has been globalised, and the younger generation need to interact with the global media, mobility and market. Amid these contrary positions, there is also another meaning constituted in the model schools. As a teacher of School A expressed, "English, Mathematics and Science including other technical subjects require good knowledge of English, so they need to be taught in English medium, whereas Social Studies and other subjects which are mostly based on our local experience and knowledge need to be taught in Nepali, it is easier for students." [Interview, 2019] It indicates that the ELS particularly concerned to EMI needs to be redefined in the schools and classrooms.

The meanings derived from the field often point out that ELS has been a conflicting zone in school and classroom spaces. In that sense, there is a debate especially in the quality of ELT and EMI in schools. Meaningful language education always requires teachers who are skilled and knowledgeable as well as able to contextualise learning materials (Meganathan, 2011). In this regard, Brown (2018) puts forth, "successful EMI requires teachers who, first of all, are proficient in English; second, who are confident in their subject matter content knowledge, and third, who have the pedagogical content knowledge and skills to teach their subject effectively to students for whom English is not their first language" (p. 24-25). As closely observed during fieldwork, the model schools require to train and orient teachers for making their classroom teaching effective. Else, converting schools to become English medium, and implementing more ELS policy without proper management of teachers, materials and learning environment could be detrimental and counterproductive. In this situation, as Meganathan (2011) claims, it is better to teach English as a subject rather than impose a bad EMI education in our model schools.

\section{ELS: Socio-cultural construction to educultural reality}

As mentioned earlier, English language education was instigated along with the establishment of modern schooling in Nepal. It was undertaken under the influence of British system of education in the then British India. Nepali society which was deeply interacting with India in terms of mobility got influenced with the British model of education. Right after the mass movement of 1950s, mass schooling movement took place in diverse villages in Nepal. These 
schools not only institutionalised more ELS in schools but also promoted deeper level attachment to English schooling in Nepali society. Thus, English language education was attributed with bikas (development), civilisation, modernisation and globalisation (Shrestha, 1997). People having modern education and English language knowledge often received higher social status as well as higher demand in the job market. On this ground, English language became a matter of social-cultural construction in Nepali society, nevertheless, they made very limited use of English language in their daily communication. However, Nepal's growing interaction with neoliberal economy after 1980s provided a good platform for spread of English throughout the nation. As a collateral force, newly established missionary schools in 1980s in the urban/semi-urban cities throughout the nation, and mushrooming English medium private schools in and after 1990s promoted ELS significantly. The interaction of Nepali citizens in transnational mobility and migration, as well as media consumption not only promoted ELS in societal space but also encouraged the schools to realise ELS as an educultural reality. Currently, as the transnational interaction of Nepali citizens via media, mobility, migration, tourism and education is mounting, educational policies and pedagogies have also been expected accordingly. On this ground, creating more ELS in schools and classrooms is often considered quite natural and significant.

However, any critical examination in school policies and pedagogies concerned to ELS often shows that the educultural reality that Nepali schools and school actors experience is found ambivalent and disjunctive. As observed in one of the classrooms of a model school, the teacher implemented English-only teaching. That steered Teacher-Talk-Time (TTT) more compared to StudentTalk-Time (STT) in the classroom. Students remained silent throughout the period of 45 minutes. The school had also formed an internal policy to make students speak English-more in its premises. Such an understanding often leads monolingual hegemony against multilingual/ plurilingual realities. Also, such an understanding hardly creates the conducive learning environment and learning opportunities to students. Many studies have pointed out that in the name of constituting more ELS, the students' mother tongue use should not be undermined. Teachers need to bring balance between English language use and the use of students' mother tongues or the languages they acquire from their childhood. Heugh and others (2007) argue that students who learn in their mother tongue can interact with the teacher, with each other and with the curricular content in ways that promote effective and efficient learning (cited in 
Brown, 2018). In order to ensure students' active participation and interaction with the teachers, fellow learners and textbooks, mother tongues need to be used as a resource. When multiple languages are employed as the learning resources, there takes place the development of multilingual competence and cross-lingual skills in the students (Gorter and Cenoz, 2017). Thus, the model school classrooms need to challenge the existing monolingual ideologies and consider students' languages as the resources for learning. Of course, ELS has now become an educultural reality, and the students need to be exposed to English language knowledge and communication skills in the globalised world today. However, it [ELS] needs to be redefined in policies and pedagogies in relation to the students' mother tongues since the latter could be the resources of student learning in model schools.

\section{Conclusion}

MSGs hardly talk about the English language, English language teaching (ELT), and medium of instruction (MI) in explicit terms. However, their internal policies and pedagogies have been affected with ELS. All these schools have defined English language, medium of instruction (MI) and more English exposure to schoolchildren as weapons of ensuring sustainability and quality service. However, analysis of the school policies, narratives of school principals, teachers and students, as well as observation fieldnotes demonstrate that ELS has been a conflicting zone for a number of reasons. Whether that is on the ground of imposed monolingual ideology against multilingual diversity, or imposed 'English more' policy even if there is no achievement of expected competencies in the students, ELS has been a matter of serious debate and confusion in schools. Very critical position that Nepal experiences is that even the contents of Moral Education, Social Studies and Local Curricula have been taught in English. Sometimes the contents of these subjects have been translated into English inaccurately, and exposed to the children accordingly in EMI. Model schools have been affected with such ill-practices of the educational market. English language-prioritised schooling, which commenced with elitist choice in the very beginning of formal schooling, was institutionalised as a socio-cultural construction later on. Now, along with the growing interaction with media, mobility and migration, it has become an educultural reality. Yet, since it manifests through uneven policies and pedagogies, it has attributed more complexities and uncertainties in the case of model school construction in Nepal. Thus, this study urges to redefine ELS in 
Unravelling English Language Space Constituted in Model School Construction...

a reciprocal relation to students' mother tongues since the latter could be utilised as the resources for student learning in model schools.

\section{References}

Awasthi, Lava Deo. (2008). Importation of ideologies from Macaulay minutes to Wood commission. Journal of Education and Research, vol. 1, pp. 21-30.

Braun, Virginia, and Clarke, Victoria. (2006). Using thematic analysis in psychology. In Qualitative Research in Psychology, pp. 77-101.

Brown, Rhona. (2018). English and its roles in education: Subject or medium of instruction? In English language teaching in Nepal: Research, reflection and practice, ed by D. Hayes. British Council. 13-34.

Devkota, Kamal Raj. (2018). Navigating exclusionary-inclusion: School experience of Dalit EFL learners in rural Nepal. Globe: A Journal of Language, Culture and Communication, 6, pp. 115-133.

Garcia, Ofelia; Skutnabb-Kangas, Tove; and Torres-Guzman, Maria E. (2009). Imagining multilingual schools: Languages in education and glocalization. Hyderabad: Orient Blackswan Private Limited.

Giri, Ram Ashish. (2010). Cultural anarchism: The consequences of privileging languages in Nepal. Journal of Multilingualism and Multicultural Development,31(1), pp.87-100. doi: 10.1080/01434630903398103.

Gorter, Durk; and Cenoz, Jasone. (2017). Language education policy and multilingual assessment. Language and Education, 31(3), pp. 231-248. doi.org/10.1080/09500782.2016.1261892.

Helot, Christine; and Laoire, Muiris O. (2011). Language policy for the multilingual classroom: Pedagogy of the possible. Bristol: Multilingual Matters.

Khanal, Peshal. (2017). Falling prey to the dominant culture? Demystifying symbolic violence against ethnic minority students in Nepal. Pedagogy, Culture and Society. 25(3). 457-467. doi.org/10.1080/14681366.2017. 1280841.

Leichty, Mark. (2003). Suitably modern: Making middle-class culture in Kathmandu. Kathmandu: Martin Chautari. 
Little, David; Leung, Constant; and Avermaet, Piet Van. (2013). Managing diversity in education. Bristol: Multilingual Matters.

Meganathan, Ramanujan. (2011). Language polciy in education and the role of English in India: From library language to language of empowerment. In Dreams and realities: Developing countries and the English language, ed. By Coleman, H. (pp. 59-87). British Council.

Ministry of Education, Science and Technology (2016). School Sector Development Plan (2016 - 2023). Sanothimi, Kathmandu, Nepal.

Ministry of Education, Science and Technology (2017). Model school directives. Sanothimi, Bhaktapur.

Park, Joseph Sung-Yul; and Wee, Lionel. (2012). Markets of English: Linguistic capital and language policy in a globalizing world. New York: Routledge.

Phyak, Prem. (2015). (En)Countering language ideologies: language policing in the ideospace of facebook. Language Policy, 14 (4). doi:10.1007/s 10993-014-9350-y.

Shrestha, Nanda. (1997). In the name of development: A reflection of Nepal. University Press of America.

Tylor, K. Shelley (2013). From 'Monolingual'multilingual classrooms to 'multilingual' multilingual Classrooms: Managing cultural and linguistic diversity in the Nepali educational system. In Little, David et al. Managing Diversity in Education: Languages, Policies and Pedagogies, (eds). (Pp. 257-272). Bristol: Multilingual Matters. 